\title{
Correction to: Association of culprit lesion plaque characteristics with flow restoration post-fibrinolysis in ST-segment elevation myocardial infarction: an intravascular ultrasound-virtual histology study
}

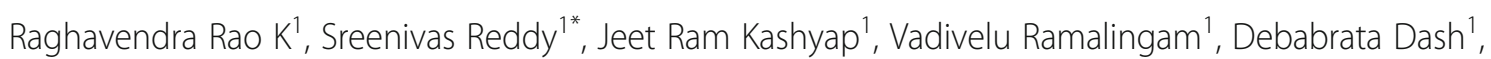

Vikas Kadiyala', Suraj Kumar ${ }^{1}$, Hithesh Reddy ${ }^{1}$, Jaspreet Kaur ${ }^{1}$, Ashok Kumar ${ }^{2}$, Naindeep Kaur ${ }^{1}$ and Anish Gupta ${ }^{1}$

Correction to: Egypt Heart J 72, 86 (2020)

https://doi.org/10.1186/s43044-020-00121-w

Following publication of the original article [1], the authors identified an error in the labelling of Figs. 1 and 2. The corrected versions of these figures have been published in this correction.

The original article [1] has been corrected.

\section{Author details}

${ }^{1}$ Department of Cardiology, Government Medical College and Hospital, Sector 32, Chandigarh 160030, India. ${ }^{2}$ Department of Neurology, Post Graduate Institute of Medical Education and Research (PGIMER), Chandigarh 160012, India.

Published online: 20 December 2020

\section{Reference}

1. Rao KR, Reddy S, Kashyap JR et al (2020) Association of culprit lesion plaque characteristics with flow restoration post-fibrinolysis in ST-segment elevation myocardial infarction: an intravascular ultrasound-virtual histology study. Egypt Heart J 72:86. https://doi.org/10.1186/s43044-020-00121-w

\footnotetext{
The original article can be found online at https://doi.org/10.1186/s43044020-00121-w.

*Correspondence: reddycardio2911@gmail.com

1 Department of Cardiology, Government Medical College and Hospital,

Sector 32, Chandigarh 160030, India

Full list of author information is available at the end of the article
}

Springer Open

(c) The Author(s). 2020 Open Access This article is licensed under a Creative Commons Attribution 4.0 International License, which permits use, sharing, adaptation, distribution and reproduction in any medium or format, as long as you give appropriate credit to the original author(s) and the source, provide a link to the Creative Commons licence, and indicate if changes were made. The images or other third party material in this article are included in the article's Creative Commons licence, unless indicated otherwise in a credit line to the material. If material is not included in the article's Creative Commons licence and your intended use is not permitted by statutory regulation or exceeds the permitted use, you will need to obtain permission directly from the copyright holder. To view a copy of this licence, visit http://creativecommons.org/licenses/by/4.0/. 


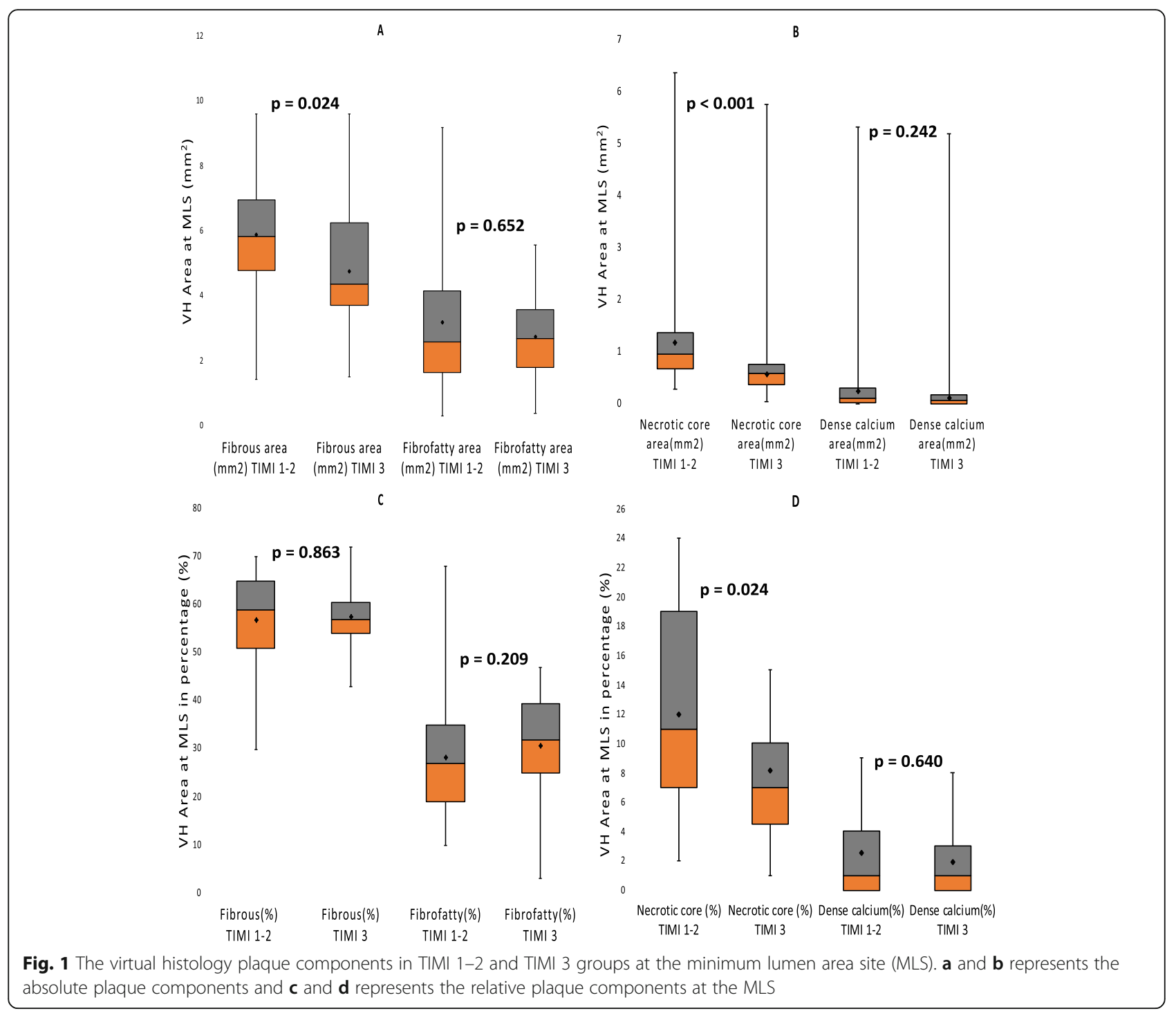




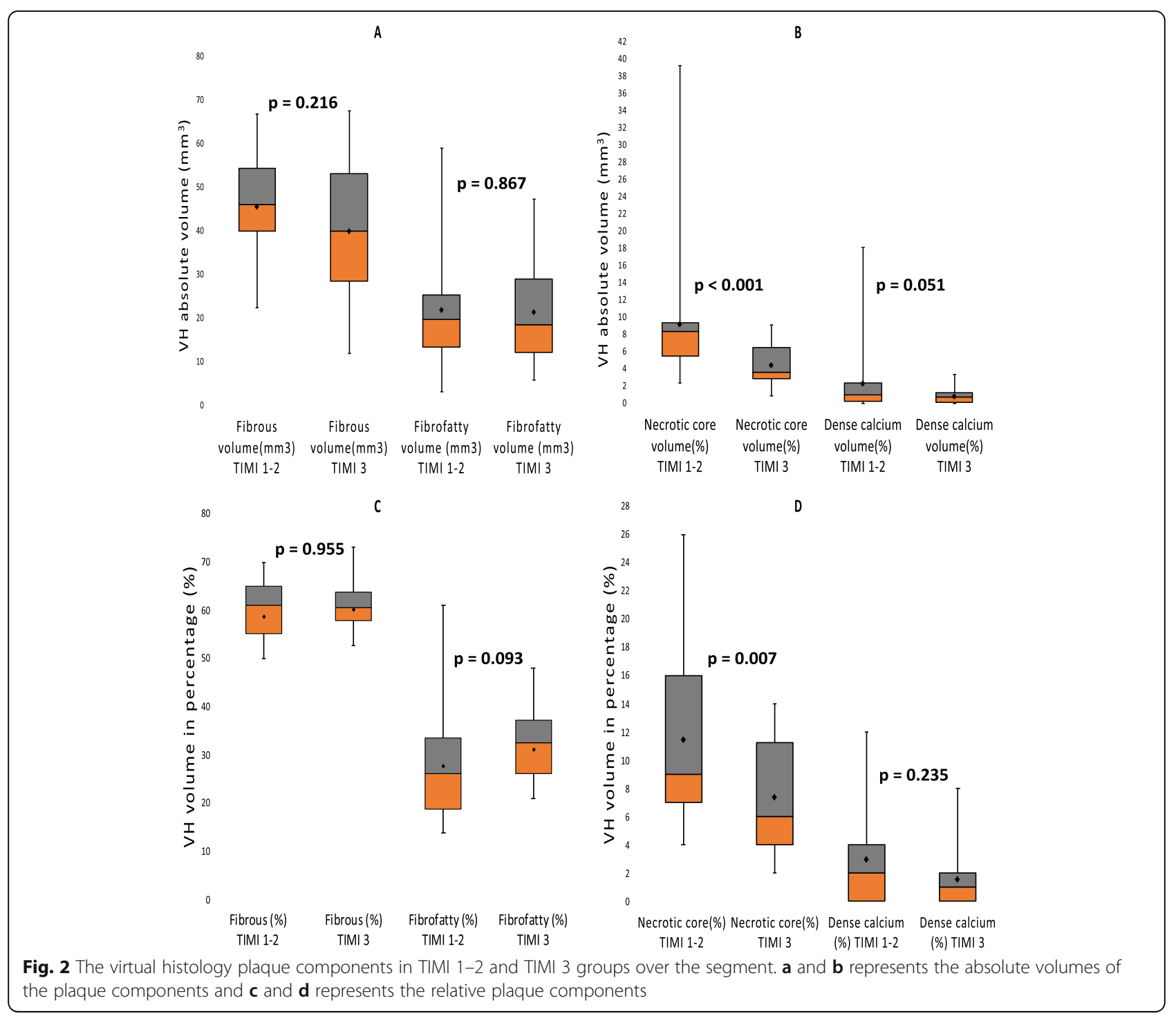

